\title{
Soil phosphorus saturation ratio for risk assessment in land use systems
}

\author{
Vimala D. Nair* \\ Soil and Water Science Department, University of Florida, Gainesville, FL, USA
}

\section{Edited by:}

Pankaj Kumar Arora, Yeungnam

University, South Korea

\section{Reviewed by:}

Gurbir S. Bhullar, Research Institute of Organic Agriculture (FiBL),

Switzerland

Gustavo Habermann, São Paulo

State University (UNESP), Brazil

Bing-Jie Ni, The University of

Queensland, Australia

*Correspondence:

Vimala D. Nair, Soil and Water Science Department, University of

Florida, PO Box 110290, 2181

McCarty Hall A, Gainesville,

FL 32611, USA

e-mail:vdn@ufl.edu
The risk of phosphorus loss from agricultural soils can have serious implications for water quality. This problem has been noted particularly in sandy soils in several parts of the world including Europe (e.g., the Netherlands, Italy, and UK) and the southeastern USA. However, the capacity of a soil to retain $\mathrm{P}$ is limited and even non-sandy soils have the potential to eventually release $P$ when inorganic or organic fertilizer is added over a period of time. A threshold phosphorus saturation ratio (PSR), calculated from $\mathrm{P}, \mathrm{Fe}$, and $\mathrm{Al}$ in an oxalate or a soil test solution such as Mehlich 1 or Mehlich 3, has been recognized as a practical means of determining when a soil has reached a level of $P$ loading that constitutes an environmental risk. When soils are below a threshold PSR value, the equilibrium $P$ concentration $\left(\mathrm{EPC}_{0}\right.$ ) is minimal. Further, the soil $\mathrm{P}$ storage capacity calculated from the same data is directly linked to the strength of $\mathrm{P}$ bonding $\left(\mathrm{K}_{\mathrm{L}}\right)$ as determined from Langmuir isotherms, and $K_{D}$, the distribution coefficient related to the strength of sorption. While the PSR is occasionally used as a predictor of the onset of environmentally significant $P$ loss from a soil, the procedure might be adopted as a routine soil test.

Keywords: Langmuir, linear isotherm, Mehlich 1, Mehlich 3, oxalate, phosphorus risk assessment, soil P storage capacity, threshold phosphorus saturation ratio

\section{INTRODUCTION}

Non-point source pollution from agricultural and other anthropogenic sources have been identified as the major cause of degradation of water bodies (USEPA, 2002). Excess application of inorganic or organic phosphorus $(\mathrm{P})$ fertilizers beyond that required for plant uptake would result in the loss of $\mathrm{P}$ from the soil to adjacent water bodies through surface or subsurface movement (Sims et al., 1998; Hooda et al., 2000; Sharpley and Tunney, 2000). Phosphorus loss from agricultural lands has an adverse impact on water quality and therefore affects human and animal health, biodiversity, nutrient cycling, and ecosystem functioning in addition to recreational facilities such as swimming and fishing. Eutrophication of surface waters has been noted in various parts of the world including the Netherlands and Italy (Breeuwsma and Silva, 1992), Florida (Nair et al., 1995), and other parts of the southeastern USA where the soils are predominantly sandy (Sims et al., 1998). However, all soils have a finite capacity to retain $\mathrm{P}$ and continued application of fertilizers even to soils that have high $P$ retention capabilities, will ultimately reach the environmental limit for safe storage of $\mathrm{P}$. This review is on the $\mathrm{P}$ saturation ratio (PSR) concept where the threshold value is an indicator for risk assessment in land use systems.

Since the ability of soils to retain $\mathrm{P}$ varies substantially, $\mathrm{P}$ loss from a soil is heavily dependent on the soil components that retain P. Determining when a soil has reached a level of P loading in agricultural and related land-use systems that constitutes an environmental risk is indeed challenging. The degree of phosphorus saturation (DPS) was first introduced in the Netherlands as a tool to predict environmental limits for soil P in sandy soils (van der Zee et al., 1987; Breeuwsma and Silva, 1992) but has since been extended to other parts of the world. The DPS is normally expressed as a percentage and calculated as the ratio of acid ammonium oxalate-extractable $[\mathrm{P}]$ to $[\mathrm{Al}+\mathrm{Fe}]$ (van der Zee and van Riemsdijk, 1988).

$$
D P S_{O X}=\frac{\text { Oxalate }- \text { extractable } P}{\alpha \text { Oxalate }- \text { extractable }[\mathrm{Fe}+\mathrm{Al}]} \times 100
$$

While the original method of calculation of the DPS specified oxalate-extractable $P, F e$, and $A l$, modifications were based on soil test phosphorus parameters used in various parts of the USA. Mehlich 1 extracts $\left(D P S_{\mathrm{M} 1}\right.$ ) (Nair and Graetz, 2002; Beck et al., 2004; Nair et al., 2004) and Mehlich 3 extracts (DPS $S_{\mathrm{M} 3}$ ) (Maguire and Sims, 2002; Sims et al., 2002; Nair et al., 2004) have been shown to be suitable to calculate DPS for sandy soils of the southeastern USA. Included in the DPS calculation is an empirical $\alpha$ factor in the denominator to account for the fraction of $F e$ and $\mathrm{Al}$ responsible for $P$ sorption for soils of a given region. The corrective factor $\alpha$ may be omitted and a simple ratio of molar $P$ to molar $[\mathrm{Fe}+\mathrm{Al}]$, referred to as the PSR, used for soils with similar properties (Maguire and Sims, 2002; Nair and Harris, 2004).

Many researchers use an arbitrary value of 0.5 for $\alpha$ (Nair et al., 2004) though others such as Paulter and Sims (2000) specified a value of 0.68 for their soils.

The PSR (or DPS) is related to soil solution $P$ concentration, and allows an establishment of threshold values corresponding approximately to a set critical solution concentration (Breeuwsma and Silva, 1992; Nair et al., 2004). A plot of water soluble $P$ (WSP) against the PSR (or DPS) illustrates this concept using $P, F e$, and $A l$ in an oxalate solution in the calculations (Figure 1). Sharpley et al. (2013) have pointed out that recently attempts have been made "to quantify the concept both from parameterized models 


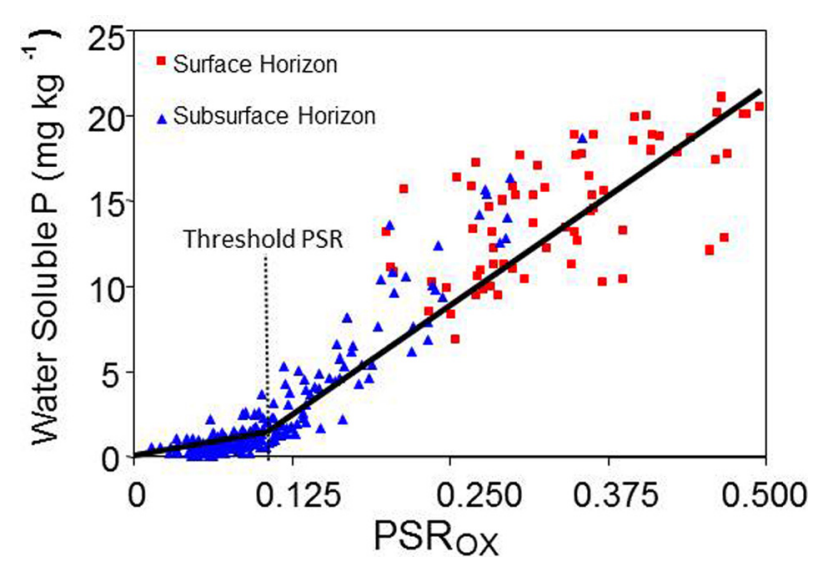

FIGURE 1 | Relationship between the concentration of water soluble phosphorus (WSP) and the phosphorus saturation ratio (PSR) for manure-impacted surface and subsurface horizons. The threshold PSR $=$ 0.1. Source: Modified from Nair et al. (2004), replacing the degree of phosphorus saturation (DPS) with PSR.

describing $P$ sorption isotherms to models describing $P$ sorption saturation." In a groundwater field monitoring study in Delaware, Andres and Sims (2013) showed that the use of the PSR concept and the calculated soil $P$ storage capacity (SPSC; see below) were effective in risk assessment of $P$ loss from the site.

\section{APPLICATION OF THE PSR CONCEPT TO NON-SANDY SOILS}

The PSR concept was originally developed for sandy soils where leaching is a primary mode of $\mathrm{P}$ transport. However, subsurface horizons of major soil orders such as the Bt horizon of Ultisols in Florida can have loamy to clayey textures, and Chakraborty et al. (2012) identified a threshold PSR for these horizons as well. Their results also showed that even when there is an abundance of crystalline components that contribute to P sorption above the threshold PSR, the most tenaciously-bound P is associated with non-crystalline metal oxides such as those extracted by an oxalate or a soil test solution such as Mehlich 1 or Mehlich 3. Further, the authors identified a threshold PSR for Bh horizons, which have organically-complexed Al. The Bh horizon occurs in Spodosols, the most extensively-occurring soil order in Florida, USA. Therefore, the PSR concept appears applicable to a wide range of soil types and not just sandy soils or soils with inorganically-complexed Al.

\section{SOIL PSR FOR WETLAND SOILS}

Preliminary data collected on wetland soils (Mukherjee et al., 2009) suggested that the threshold PSR might be a practical indicator to assess nutrient enrichment in wetland soils where $\mathrm{P}$ solubility is regulated by $\mathrm{Fe}$ and Al. More recent work (Nair and Reddy, 2013) confirmed the applicability of the PSR concept to inundated soils. When occurring on the same landscape, the threshold PSR value is identical to that of adjacent upland soils. This threshold PSR has been identified as 0.1 for a range of upland (Nair et al., 2010) and wetland (Nair and Reddy, 2013) soils in Florida, USA. The organic matter in the wetland soil does not contribute to P sorption below the threshold PSR. In the Nair and Reddy (2013) study, organic matter ranged from 0 to $95 \%$ for wetland soils both above and below the threshold value, confirming that below the 0.1 threshold, $\mathrm{P}$ retention is dictated only by $\mathrm{Fe}$ and $\mathrm{Al}$.

\section{THRESHOLD PSR VALUES FOR A RANGE OF LOCATIONS AND SOIL TYPES}

A literature review of various studies on DPS/PSR by researchers in different parts of the world showed a remarkable similarity in the threshold PSR value (Table 1) for all soils-located on Alfisols, Entisols, Inceptisols, Mollisols, Oxisols, Spodosols Ultisols, or Vertisols. While the WSP-PSR relationship is often used in determining the threshold PSR value, some researchers (Sims et al., 2002) identified threshold PSR values using runoff in rainfall simulation experiments as a function of soil PSR. Some other procedures used are identified in Table 1. Further, the PSR itself is determined using different extractants such Mehlich 1, Mehlich 3, or oxalate.

When $\mathrm{P}$ sorption maximum ( $\mathrm{P}$ fixation maximum) is used instead of $[\mathrm{Fe}+\mathrm{Al}]$, the $\alpha$ value is not specified and it is not clear how this parameter can be related to [Fe $+\mathrm{Al}]$ in PSR calculations. Despite these variations in methodology for the threshold PSR calculations, the value appears to be in the $0.10-0.15$ range (Table 1). The PSR determination appears to be operationally dependent; however, it could eventually be possible to obtain a single threshold PSR value for a range of soils if the method of PSR determination is maintained the same.

The PSR values are soil-specific and not system-specific, i.e., two soils can have the same PSR, but the environmental risk would be different because the $\mathrm{P}$ retentive properties of the soils are different. However, once a threshold PSR is determined for a group of soils with similar properties (such as soils with inorganically-complexed $\mathrm{Al}$ or organo-Al complexed horizons such as the Bh horizon), then a more quantitative measure, the soil P storage capacity (SPSC) can be calculated (see the next Section).

\section{OBTAINING ISOTHERM PARAMETERS FROM SOIL TEST DATA}

Since the strength of $\mathrm{P}$ bonding in the Langmuir adsorption model is an indicator of how firmly $\mathrm{P}$ is held to soil components such as $\mathrm{Fe}$ and $\mathrm{Al}$, it follows that below the threshold PSR Langmuir $\mathrm{K}_{\mathrm{L}}$, the $\mathrm{P}$ bonding constant should be high and the $\mathrm{P}$ would be released from the soil to the water once the threshold PSR is reached (Dari et al., 2012). Therefore the PSR value obtained from a soil testing solution such as Mehlich 1 or Mehlich 3 can be used to predict when a soil will begin to become an environmental P loss risk. Below the threshold PSR, the equilibrium $\mathrm{P}$ concentration $\left(\mathrm{EPC}_{0}\right)$ of a soil will be a minimum, but will increase once the soil is above the threshold value (Chakraborty et al., 2012).

The amount of $\mathrm{P}$ that can be safely stored within a soil prior to the soil becoming an environmental risk can be calculated from the threshold PSR (Nair and Harris, 2004). The soil P storage capacity (SPSC) is calculated using the following generalized equation: 
Table 1 | Threshold P saturation ratio (PSR) and the corresponding degree of P saturation (DPS) for surface soils from various locations and soil orders.

\begin{tabular}{|c|c|c|c|c|c|}
\hline Location & Soil order & Procedure $^{\dagger}$ & PSR & DPS (\%) & References \\
\hline & & M3-PSR vs. column leachate & 0.21 & & \\
\hline \multirow[t]{2}{*}{ Florida, USA (uplands) } & Entisols/Ultisols & Ox-PSR vs. WSP & 0.10 & 20 & Nair et al., 2004 \\
\hline & & M3-PSR vs. WSP & 0.08 & 16 & \\
\hline Florida, USA (wetlands) & Spodosols & M1-PSR vs. WSP & 0.10 & N/A & Nair and Reddy, 2013 \\
\hline Minnesota, USA & Alfisols/Mollisols & M3-PSR vs. WSP & 0.11 & 22 & Laboski and Lamb, 2004 \\
\hline Brazil & Ultisols & $\begin{array}{l}\text { M3-P/P sorption maximum vs. } \\
\text { WSP }\end{array}$ & $0.23^{\mathrm{a}}$ & 23 & Abdala et al., 2012 \\
\hline Canada & N/A & M3-P/M3-Al & 0.08 & 15 & Khiari et al., 2000 \\
\hline Switzerland & $\mathrm{N} / \mathrm{A}$ & Ox-PSR vs. WSP & 0.12 & 24 & Roger et al., 2014 \\
\hline UK & Various & Ox-PSR vs. desorbed P & 0.10 & 10 & Hooda et al., 2000 \\
\hline Uganda & Oxisols & M3-PSR vs. WSP & 0.10 & 20 & $\begin{array}{l}\text { Nkedi-Kizza and Nair, } \\
\text { unpublished }\end{array}$ \\
\hline
\end{tabular}

tProcedures used in the threshold PSR determinations vary including replacing water soluble $P$ (WSP) with runoff $P$ from rainfall simulation experiments or leachate from column experiments.

${ }^{\ddagger}$ Ox-PSR, M3-PSR, and M1-PSR; Threshold P saturation ratio determined from P, Fe, and Al in oxalate, Mehlich 3 and Mehlich 1 solutions, respectively. ${ }^{a} \alpha$ considered to be 1 in the PSR calculations.

N/A Not available.

$$
\begin{aligned}
\text { SPSC }= & (\text { Threshold PSR }- \text { Soil PSR }) \\
& *[\mathrm{Fe}+\mathrm{Al}] * 31 \mathrm{mg} \mathrm{kg}^{-1}
\end{aligned}
$$

where $\mathrm{P}, \mathrm{Fe}$, and $\mathrm{Al}$ can be determined in either an oxalate or a soil test solution. Below the threshold PSR (e.g., 0.1), SPSC is positive (the soil is a $\mathrm{P}$ sink) while SPSC becomes negative (soil is a $\mathrm{P}$ source) above the threshold value. This concept has been shown to be applicable to subsurface soil horizons (Chakraborty et al., 2011) and wetland soils (Reddy et al., 2012; Nair and Reddy, 2013) as well. The SPSC has an additional advantage in that it is able to provide a more meaningful and valued $\mathrm{P}$ loss risk indicator (Nair and Harris, 2004) since it takes into account previous P loading and enables a prediction of the amount of $\mathrm{P}$ that can be added to a soil prior to the soil becoming an environmental risk. Below a threshold PSR (i.e., when SPSC is positive), SPSC is related to Langmuir $\mathrm{K}_{\mathrm{L}}$ (Dari et al., 2012), allowing prediction of $\mathrm{K}_{\mathrm{L}}$ values from soil test data.

\section{SUMMARY AND CONCLUSIONS}

The threshold PSR has enormous power in predicting $\mathrm{P}$ stability in a soil with values below the threshold value indicating that $\mathrm{P}$ release from the soil is minimal. Once the threshold PSR is reached, the soil becomes a $\mathrm{P}$ source. While the PSR concept was originally developed for sandy surface soils, recent research indicated its validity for subsurface horizons including soils that have loamy to clayey textures. Further, the approach is applicable to wetland soils where the organic matter does not contribute to $\mathrm{P}$ retention below the threshold value. Therefore, determination of the PSR of soils (surface and/or subsurface) affords a procedure to predict when $\mathrm{P}$ loss from a site via runoff or leaching would begin to become an environmental concern. Despite methodology differences in obtaining a threshold PSR value, most soils tend to have a PSR value in the $0.1-0.15$ range. Since SPSC can be calculated from the same data that is required for PSR calculations; it follows that both the PSR and the SPSC can be obtained by sending a soil sample to a routine soil testing lab. The PSR/SPSC concept can be easily adopted by farmers and others who are interested in management practices that minimize the risk of $\mathrm{P}$ loss from soils.

\section{ACKNOWLEDGMENTS}

The author thanks Willie Harris for comments and suggestions on an earlier version of the review.

\section{REFERENCES}

Abdala, D. B., Ghosh, A. K., da Silva, I. R., de Novias, R. F., and Venegas, V. H. A. (2012). Phosphorus saturation of a tropical soil and related P leaching caused by poultry litter addition. Agric. Ecosyst. Environ. 162, 15-23. doi: 10.1016/j.agee.2012.08.004

Andres, A. S., and Sims, J. T. (2013). Assessing potential impacts of a wastewater rapid infiltration basin system on groundwater quality: a Delaware case study. J. Environ. Qual. 42, 391-404. doi: 10.2134/jeq2012.0273

Beck, M. A., Zelazny, L. W., Daniels, W. L., and Mullins, G. L. (2004). Using the Mehlich 1 extract to measure soil phosphorus saturation for environmental 
risk assessment. Soil Sci. Soc. Am. J. 68, 1762-1771. doi: 10.2136/sssaj 2004.1762

Breeuwsma, A., and Silva, S. (1992). "Phosphorus fertilisation and environmental effects in The Netherlands and the Po Region (Italy)," in Report 57. Agricultural Research Department (Wageningen: The Winand Staring Centre for Integrated Land, Soil, and Water Research).

Chakraborty, D., Nair, V. D., Chrysostome, M., and Harris, W. G. (2011). Soil phosphorus storage capacity in manure-impacted Alaquods: implications for water table management. Agric. Ecosyst. Environ. 142, 167-175. doi: 10.1016/j.agee.2011.04.019

Chakraborty, D., Nair, V. D., Harris, W. G., and Rhue, R. D. (2012) Environmentally-relevant phosphorus retention capacity of sandy coastal plain soils. Soil Sci. 177, 701-707. doi: 10.1097/SS.0b013e31827d8685

Dari, B., Nair, V. D., Rhue, R. D., and Mylavarapu, R. (2012). "Relationship of Langmuir parameters to the soil phosphorus saturation ratio," in ASA/CSSA/SSSA 2012 International Annual Meetings (Cincinnati, OH: CD Rom Publication).

Hooda, P. S., Rendell, A. R., Edwards, A. C., Withers, P. J. A., Aitken, M. N., and Truesdale, V. W. (2000). Relating soil phosphorus indices to potential phosphorus release to water. J. Environ. Qual. 29, 1166-1171. doi: $10.2134 /$ jeq2000.00472425002900040018x

Indiati, R., and Sequi, P. (2004). Phosphorus intensity-quantity relationships in soils highly contrasting in phosphorus adsorption properties. Commun. Soil Sci. Plant Anal. 35, 131-143. doi: 10.1081/CSS-120027639

Khiari, L., Parent, L. E., Pellerin, A., Alimi, A. R. A., Tremblay, C., Simard, R. R., et al. (2000). An agri-environmental phosphorus saturation index acid coarse-textured soils. J. Environ. Qual. 29, 1561-1567. doi: $10.2134 /$ jeq2000.00472425002900050024x

Laboski, C. A. M. and Lamb, L. A. (2004). Impact of manure application on soil phosphorus sorption characteristics and subsequent water quality implications. Soil Sci. 169, 440-448. doi: 10.1097/01.ss.0000131229.58849.0f

Maguire, R. O., and Sims, J. T. (2002). Soil testing to predict phosphorus leaching. J. Environ. Qual. 31, 1601-1609. doi: 10.2134/jeq2002.1601

Mukherjee, A., Nair, V. D., Clark, M. W., and Reddy, K. R. (2009). Development of indices to predict phosphorus release from wetland soils. J. Environ. Qual. 38, 878-886. doi: 10.2134/jeq2008.0230

Nair, V. D., and Graetz, D. A. (2002). Phosphorus saturation in spodosols impacted by manure. J. Environ. Qual. 31, 1279-1285. doi: 10.2134/jeq2002.1279

Nair, V. D., Graetz, D. A., and Portier, K. M. (1995). Forms of phosphorus in soil profiles from dairies of South Florida. Soil Sci. Soc. Am. J. 59, 1244-1249. doi: 10.2136/sssaj1995.03615995005900050006x

Nair, V. D., and Harris, W. G. (2004). A capacity factor as an alternative to soil test phosphorus in phosphorus risk assessment. N.Z. J. Agric. Res. 47, 491-497. doi: 10.1080/00288233.2004.9513616

Nair, V. D., Harris, W. G., Chakraborty, D., and Chrysostome, M. (2010) Understanding Soil Phosphorus Storage Capacity. SL 336. Available online at http://edis.ifas.ufl.edu/pdffiles/SS/SS54100.pdf

Nair, V. D., Portier, K. M., Graetz, D. A., and Walker, M. L. (2004). An environmental threshold for degree of phosphorus saturation in sandy soils. J. Environ. Qual. 33, 107-113. doi: 10.2134/jeq2004.1070

Nair, V. D., and Reddy, K. R. (2013)."Phosphorus sorption and desorption in wetland soils," in Methods on Biogeochemistry of Wetlands, eds R. DeLaune, K. R. Reddy, C. J. Richardson, and P. Megonigal (Madison, WI: SSSA, Inc.), 667-678.

Paulter, M. C., and Sims, J. T. (2000). Relationships between soil test phosphorus, soluble phosphorus, and phosphorus saturation in delaware soils. Soil Sci. Soc. Am. J. 64, 765-773. doi: 10.2136/sssaj2000.642765x
Reddy, K. R., Clark, M. W., and Nair, V. D. (2012). Legacy Phosphorus in Agricultural Watersheds: Implications for Restoration and Management of Wetlands and Aquatic Systems. International Atomic Energy Agency (IAEA) Newsletter. Available online at: http://www-naweb.iaea.org/nafa/swmn/public/SNL-342.pdf.

Roger, A., Sinaj, S., Libohova, Z., and Frossard, E. (2014). "Regional investigation of soil phosphorus saturation degree, a study case in Switzerland," in GlobalSoilMap: Basis of the Global Spatial Soil Information System, eds D. Arrouays, N. McKenzie, J. Hempel, A. Richer de Forges, and A. B. McBratney (London: Taylor and Francis Group), 79-83. doi: 10.1201/ b16500-18

Sharpley, A., Jarvie, H. P., Buda, A., May, L., Spears, B., and Kleinman, P. (2013). Phosphorus legacy: practices to mitigate future water quality impairment. J. Environ. Qual. 42, 1308-1326. doi: 10.2134/jeq2013.03.0098

Sharpley, A., and Tunney, H. (2000). Phosphorus research strategies to meet agricultural and environmental challenges in the $21^{\text {st }}$ century. J. Environ. Qual. 29, 176-181. doi: 10.2134/jeq2000.00472425002900 $010022 \mathrm{x}$

Sims, J. T., Maguire, R. O., Leytem, A. B., Gartley, K. L., and Paulter, M. C. (2002) Evaluation of Mehlich 3 as an agri-environment soil phosphorus test for the Mid-Atlantic United States of America. Soil Sci. Soc. Am. J. 66, 2016-2032. doi: 10.2136/sssaj2002.2016

Sims, J. T., Simard, R. R., and Joern, B. C. (1998). Phosphorus loss in agricultural drainage: historical perspective and current research. J. Environ. Qual. 27, 277-293. doi: 10.2134/jeq1998.004724250027000 20006x

U. S. Environmental Protection Agency (USEPA). (2002). Environmental Indicators of Water Quality in the United States. EPA 841-R-02-001. Washington, DC: USEPA Office of Water Quality.

Vadas, P. A., Kleinman, P. J. A., Sharpley, A. N., and Turner, B. L. (2005). Relating soil phosphorus to dissolved phosphorus in runoff: a single extraction coefficient for water quality modeling. J. Environ. Qual. 34, 572-580. doi: 10.2134/jeq2005.0572

van der Zee, S. E. A. T. M., Fokkink, L. G. J., and van Riemsdijk, W. H. (1987) A new technique for assessment of reversibly adsorbed phosphate. Soil Sci. Soc. Am. J. 51, 599-604. doi: 10.2136/sssaj1987.036159950051000 30009x

van der Zee, S. E. A. T. M., and van Riemsdijk, W. H. (1988). Model for longterm phosphate reaction kinetics in soil. J. Environ. Qual. 17, 35-41. doi: $10.2134 /$ jeq1988.00472425001700010005x

Conflict of Interest Statement: The author declares that the research was conducted in the absence of any commercial or financial relationships that could be construed as a potential conflict of interest.

Received: 06 February 2014; paper pending published: 05 March 2014; accepted: 22 March 2014; published online: 10 April 2014.

Citation: Nair VD (2014) Soil phosphorus saturation ratio for risk assessment in land use systems. Front. Environ. Sci. 2:6. doi: 10.3389/fenvs.2014.00006

This article was submitted to Agroecology and Land Use Systems, a section of the journal Frontiers in Environmental Science.

Copyright (c) 2014 Nair. This is an open-access article distributed under the terms of the Creative Commons Attribution License (CC BY). The use, distribution or reproduction in other forums is permitted, provided the original author(s) or licensor are credited and that the original publication in this journal is cited, in accordance with accepted academic practice. No use, distribution or reproduction is permitted which does not comply with these terms. 